\title{
Home treatment for chronic respiratory failure in children: a prospective study
}

\author{
B. Fauroux*, A. Sardet*, D. Foret* \\ For the paediatric group on behalf of ANTADIR
}

Home treatment for chronic respiratory failure in children: a prospective study. $B$. Fauroux, A. Sardet, D. Foret. For the paediatric group on behalf of ANTADIR. (OERS Journals Ltd 1995.

ABSTRACT: Home treatment for children with chronic respiratory failure (CRF) is increasing. However, the causes of CRF in children and the details of their home treatment are not well-known. The aim of this study was to describe the causes of $\mathrm{CRF}$ in the paediatric population and the treatments that the patients received at home.

We surveyed all children (aged $\leq 18$ yrs) entering the Association Nationale pour le Traitement à Domicile de l'Insuffisance Respiratoire chronique (ANTADIR) for home treatment of CRF between March 1992 and March 1993.

Two hundred and eighty seven children ( 178 boys, $62 \%)$ started home treatment for CRF during the year. One hundred and eleven patients had obstructive respiratory disease: cystic fibrosis (CF) $(n=24)$; bronchopulmonary dysplasia (BPD) $(n=79)$; other obstructive respiratory disease $(n=8)$. One hundred and seventy six patients had restrictive lung disease: neuromuscular disease $(n=87)$; $k$ pyposcoliosis $(n=21)$; pulmonary fibrosis $(n=6)$; cardiac disease $(n=14)$; stomatological disease $(n=10)$; other restrictive respiratory disease $(n=9)$; and 29 miscellaneous causes. One hundred and thirteen patients received oxygen therapy, with a mean daily use of $17.7 \mathrm{~h}$

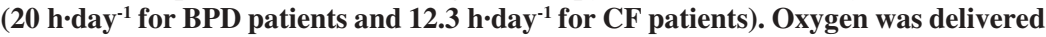
by a concentrator in $88 \%$ of cases. One hundred and fifty eight children received mechanical ventilation (MV). Five children received nasal continuous positive airway pressure ventilation for sleep apnoea, four had pneumatic belt ventilation, and 12 had a tracheostomy without MV. Treatment was stopped in 21 children, because of death in nine and improvement in the other 12.

Home treatment for children with CRF is well developed in France via the ANTADIR network. Causes of CRF in children are heterogeneous, with a relatively good prognosis.

Eur Respir J., 1995, 8, 2062-2066.
*Association Nationale pour le Traitement à Domicile del'Insuffisance Respiratoire chronique (ANTADIR), Paris, France.

Correspondence: B. Fauroux

ANTADIR

66 Bd St Michel

75006 Paris

France

Keywords: Children

chronic respiratory failure

home treatment

mechanical ventilation

oxygen therapy

Received: February 31995

Accepted after revision June 241995

Members of the paediatric group of ANTADIR: F. Bremont, M.F. Delaperche, I. Desguerre, B. Estournet, B. Fauroux, D. Foret, M.P. Humeau, B. Marchal, B. Monier, I. Pin, A. Sardet, M.C. Lelong-Tissier, C. Wood
Over the last $10 \mathrm{yrs}$, there has been unprecedented emphasis on home-care for chronically ill children, including ventilator-dependent children. Advances in medical knowledge and technology have contributed to improved survival rates for critically ill children. There is now an increasing pressure to minimize health-care costs and to expedite the transition from hospital to home. Medical equipment has been designed to accommodate home-care needs. The psychological and developmental advantages of home-care for chronically ill children are well-recognized [1,2].

The two major home treatments for children suffering from chronic respiratory failure (CRF) are long-term oxygen therapy (LTOT) and mechanical ventilation (MV). LTOT is justified in the case of chronic hypoxaemia despite optimal pharmacological treatment. In the absence of universally accepted criteria for starting LTOT in children, treatment is recommended in one of the following situations: 1) a hypoxaemia $3 \mathrm{SD}$ below the normal whilst breathing room air adjusted for age in a steady-state in an infant or young child [3];2) sleep desaturation periods with an arterial oxygen saturation $<90 \%$ for more than $20 \%$ of the nocturnal study period; and 3) the presence of pulmonary hypertension and/or right ventricular hypertrophy and/or polycythaemia due to chronic hypoxaemia, but these signs are rarely encountered in children. The prime indication for the use of home MV is chronic alveolar hypoventilation with associated respiratory failure as indicated by hypoxaemia and hypercapnia. Hypoxaemia is defined as cited above and hypercapnia is defined as an arterial carbon dioxide tension $\left(\mathrm{Pa}_{\mathrm{a}}, \mathrm{CO}_{2}\right) 6.0 \mathrm{kPa}(>45$ $\mathrm{mmHg}$ ) (which represents $+2 \mathrm{SD}$ ) independent of the child's age. Chronic alveolar hypoventilation may occur in children with airway or parenchymal lung disease or in children with normal lungs. In the latter instance, central nervous system dysfunction or thoracic abnormalities, such as chest wall deformity or neuromuscular disease, may be responsible for the hypo-ventilation.

Few studies have been published regarding home MV and LTOT in children [4-12]. SAUVE et al. [4] reported the outcome in the cases of 44 infants discharged home from neonatal intensive care unit on LTOT. The infant's 
discharge diagnosis were bronchopulmonary dysplasia (BPD) $(n=39)$, sleep apnoea $(n=2)$ and congenital cardiac defects $(n=3)$. The five infants who had diagnoses other than BPD all died, but 34 of 39 infants with BPD survived the 3 yrs follow-up. RoBINSON [5] reported 24 ventilatordependent children in the United Kingdom, but only 10 were managed at home. Causes of CRF were heterogeneous and could be divided into four groups, namely generalized neuromuscular disease; high cervical cord disease, nocturnal hypoventilation or chronic lung disease. Six of the 24 children died. This author emphasized that the prevalence of such children appears to be increasing. The Association Nationale pour le Traitement à Domicile de l'Insuffisance Respiratoire chronique (ANTADIR) is a French national nonprofit-making network that serves over 35,000 ventilator-assisted and/or oxygen-dependent adults and children. ANTADIR is responsible for nearly all ventilator-dependent patients and $70 \%$ of those receiving home oxygen therapy in France. The other 30\% are looked after by private networks [13].

The aim of this study was to survey all children aged $\leq 18$ yr entering the ANTADIR for home treatment for CRF in order to examine the causes of CRF and the treatments which were performed.

\section{Materials and methods}

ANTADIR is a national organization which federates 33 regional associations distributed all over France. Twenty two of these regional associations participated in the study. The number of patients cared for by these 22 associations represents $78 \%$ of the total number of ANTADIR patients on January 1, 1992.

All children (aged $\leq 18$ years) entering any of these associations between March 1992 and March 1993 were included in the study. A questionnaire was completed at entry by a physician of the regional association, concerning the child's birth date and gender, the cause of CRF, the treatment and school attendance. Any change of treatment was registered on a second questionnaire during the study year.

The data processing was performed anonymously using Excel data-base programme.

\section{Results}

During the specified study period, 287 children (178 boys, $62 \%$ ) started home-care for CRF. By that time, children represented $3.2 \%$ of the total number of patients (adults and children) entering these associations over that period. Mean age of the children was 7.5 yrs (range 1 month to $18 \mathrm{yrs}$ ); $45 \%$ were younger than 2 yrs of age (fig. 1).

Causes of CRF were varied (fig. 2). One hundred and eleven patients had an obstructive respiratory disease: cystic fibrosis $(\mathrm{CF})(\mathrm{n}=24)$; BPD $(\mathrm{n}=79)$; other obstructive respiratory disease $(n=8)$. One hundred and seventy six patients had restrictive lung disease: neuromuscular disease $(n=87)$; kyphoscoliosis $(n=21)$; pulmonary fibrosis

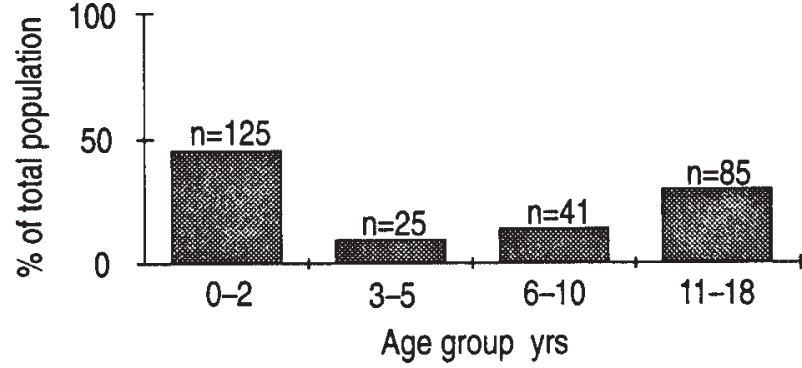

Fig. 1. - Distribution of the total population according to age groups (age is known for 276 of the 287 children).

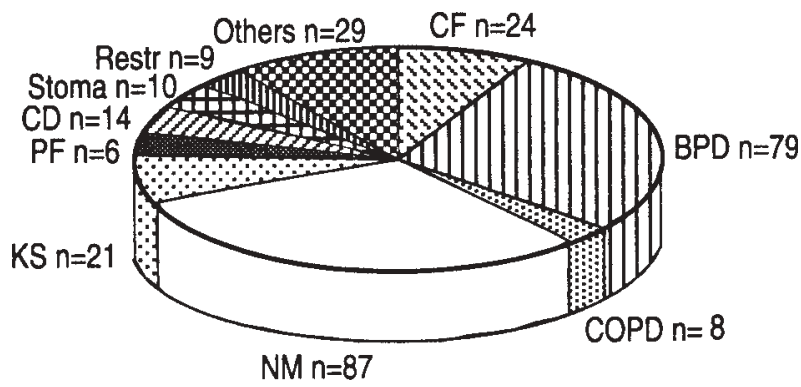

Fig. 2. - Causes of chronic respiratory failure. Obstructive lung disease - CF: cystic fibrosis; BPD: bronchopulmonary dysplasia; COPD: chronic obstructive pulmonary disease. Restrictive lung disease - NM: neuromuscular disease; KS: kyphoscoliosis; PF: pulmonary fibrosis; CD: cardiac disease; Stoma: stomatological disease; Restr: other restrictive respiratory disease; Others: miscellaneous.

$(n=6)$; cardiac disease $(n=14)$; stomatological disease $(n=10)$; other restrictive respiratory disease $(n=9)$; and 29 miscellaneous causes. Table 1 shows the details of the 29 children with more uncommon causes of CRF. Stomatological disease represents a heterogeneous group of children suffering from Pierre Robin syndrome, vocal cord paralysis, neuropolysaccharidosis and obstructive apnoea.

Figure 3 details the equipment used at home. One hundred and thirteen $(39 \%)$ children received LTOT, with a mean daily use of $17.7 \mathrm{~h}$ (range 6-24 h.day ${ }^{-1}$ ). Mean prescribed daily oxygen use differed according to the cause of CRF, with BPD and CF patients using LTOT for a mean

Table 1. - Detail of the other causes of chronic respiratory failure (CRF) and the equipment used at home

\begin{tabular}{lcl}
\hline Causes of CRF & Pts & Equipment \\
\hline $\begin{array}{l}\text { ENT disease } \\
\text { Cranial trauma }\end{array}$ & 7 & $\begin{array}{l}\text { Tracheostomy } \\
\text { Tracheostomy + } \\
\text { (MV in 4 patients) }\end{array}$ \\
$\begin{array}{l}\text { Ondine's disease } \\
\text { Bone disease with } \\
\text { thoracic deformity }\end{array}$ & 5 & $\begin{array}{l}\text { LTOT-MV-CPAP } \\
\text { Pressure preset ventilation }\end{array}$ \\
$\begin{array}{l}\text { Scoliosis } \\
\text { Lung surgery }\end{array}$ & 3 & $\begin{array}{l}\text { Pressure preset ventilation } \\
\text { LTOT-pressure preset } \\
\text { ventilation } \\
\text { Spinal cord injury }\end{array}$ \\
ARDS sequelae & 1 & $\begin{array}{l}\text { Tracheostomy with MV } \\
\text { LTOT }\end{array}$ \\
\hline
\end{tabular}

ENT: ear nose and throat disease; ARDS: adult respiratory distress syndrome; MV: mechanical ventilation; LTOT: long-term oxygen therapy; CPAP: continuous positive airway pressure ventilation. 


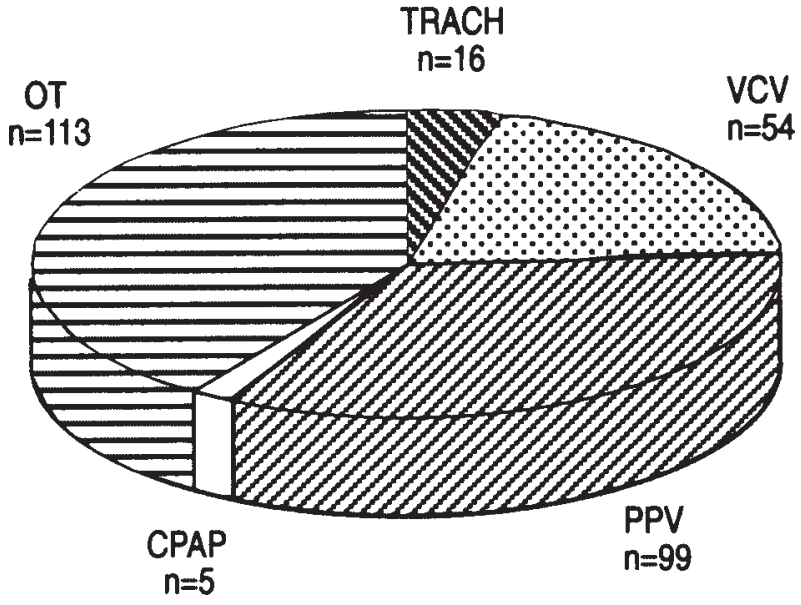

Fig. 3. - Equipment used at home. OT: oxygen therapy; VCV: volume cycled ventilation; PPV: pressure preset ventilation; CPAP: continuous positive airway pressure ventilation; TRACH: tracheostomy.

of 20 and $12.3 \mathrm{~h}$ daily, respectively. Mean prescribed oxygen flow rate was $1.45 \mathrm{~L} \cdot \mathrm{min}^{-1}$. Mean prescribed inspired oxygen concentration for a Hood was $26 \%$. Oxygen was delivered via a concentrator in $88 \%$ of children. Only $6 \%$ of children received liquid oxygen and 7\% received oxygen from a cylinder. Nearly half of the children (49\%) received oxygen via nasal prongs. Fifteen percent and $17 \%$ of the patients received oxygen via a nasal cannula and a Hood, respectively. Six percent had a cannula directly connected to a tracheostomy. Fifteen percent of the children had both nasal prongs and Hood. MV was performed in 158 children (fig. 3). Volume cycled ventilation (Eole 2E, Saime France, Monnal D and DCC, Taema France) and pressure preset ventilation (Portabird, Bird Products, Sebac, France) were performed in 54 and 99 children, respectively, with a mean daily use of 18.3 and $1 \mathrm{~h}$. Home MV was mainly performed in children with a restrictive lung disease. Neuromuscular patients used MV for a mean of $17 \mathrm{~h} \cdot \mathrm{day}^{-1}$. Patients with another restrictive disease (spinal cord injury) used MV for 20-22 h.day ${ }^{-1}$. Older children with Duchenne's dystrophy used MV during the night $\left(8-13 \mathrm{~h} \cdot\right.$ day $\left.^{-1}\right)$. With respect to infants with $\mathrm{BPD}$ ventilated at home, MV was performed for a mean of $20 \mathrm{~h} \cdot \mathrm{day}^{-1}$. Nasal intermittent positive pressure ventilation was performed during sleep in cystic fibrosis patients. Few children had continuous positive airway pressure (CPAP) ventilation or tracheostomy without LTOT or MV.

Treatment differed according to the cause of CRF (fig. 4). In some diseases, oxygen therapy or MV was used nearly

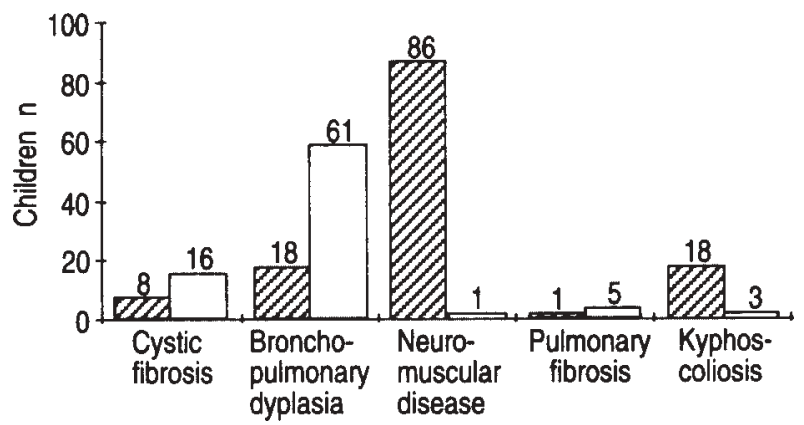

Fig. 4. - Equipment used at home for some diseases responsible for chronic respiratory failure. $\square>\square:$ mechanical ventilation; $\square$ : oxygen therapy.
Table 2. - School attendance in children aged $4 \mathrm{yrs}$ or older (response rate 67\%)

\begin{tabular}{lcc}
\hline School according to age & \multicolumn{3}{c}{ Children artesding school } \\
& $\mathrm{n}$ & s. $^{*}$ \\
\hline Nursery school (4-6 yrs) & 7 & 58 \\
Primary school (6-10 yrs) & 14 & 61 \\
College/high school (10-18) & 50 & 88 \\
\hline
\end{tabular}

*: percentage of total children in the age group.

exclusively, but in other diseases, such as BPD or CF, both treatments were performed at home. Sixteen of the $24 \mathrm{CF}$ patients used LTOT at home, the others received home MV.

School attendance was better for children attending college and high school (88\%) than for younger children (table 2).

Thirty (10\%) children stopped home treatment during the study. Nine children died, one child returned to hospital, and two children stopped treatment because of poor tolerance. Treatment was stopped in another 18 children, of whom 17 had a BPD, because of improvement of CRF.

\section{Discussion}

This large prospective study provides useful information about home LTOT and MV in children. The prevalence and incidence of home treatment for CRF children is probably underestimated. Firstly, despite the fact that most of the major ANTADIR associations participated in the study, some children looked after by other associations were not included. Secondly, in France, an unknown number of children receive home LTOT via private networks. However, because of important manpower and financial support, most children receiving home MV are cared for by ANTADIR.

CRF may occur in a heterogeneous group of diseases. The causes, treatment and prognosis of CRF differ according to the child's age and the type of disease. Children on home treatment for CRF can be divided into two groups: those with an obstructive lung disease, such as $\mathrm{CF}$, chronic obstructive respiratory disease and BPD, and those with a restrictive lung disease, such as neuromuscular disease or kyphoscoliosis, or pulmonary fibrosis. In this paediatric population, some rare causes of CRF are also represented, such as sequelae of head injury, spinal cord injury, lung surgery or ARDS.

Treatment depends on the cause of CRF. Children with bronchopulmonary disease are mainly treated with LTOT, but some of them receive MV. MV is indicated when alveolar hypoventilation is present, associated with hypercapnia and hypoxaemia. Home MV has been used for children with BPD; its use in CF patients is more recent. Noninvasive intermittent positive pressure ventilation (NIPPV) by a nasal mask has been used as a "bridge to transplantation" in patients with CF by HODSON et al. [14]. More recently, however, NIPPV has been introduced at an earlier stage with good long-term results [15-17]. NIPPV corrects alveolar hypoventilation, reduces respiratory muscle fatigue and decreases ventilation-perfusion mismatch. To our knowledge, no study has previously 
compared LTOT to MV in CF patients. The level of hypercapnia seems to be an important pathological parameter for MV. However, NIPPV is more invasive than oxygen therapy and psychological factors probably constitute an additional important component in the choice of this treatment, especially in young patients, in whom the results of lung transplantation are not as good as for older patients. NIPPV appears to slow the natural decline of lung function [16, 17]. Most of the children [18 out of 21] with kyphoscoliosis received home MV. In studies of long-term home MV, the best prognosis was observed in those patients with restrictive lung disease [18]. Most children with neuromuscular disease received home positive pressure ventilation (PPV). This type of ventilation is indicated when there is a thoracic deformity affecting the insertion of the diaphragm or a clear deficit in thoracic growth. Despite the absence of scientific evidence, this type of ventilation seems to improve the morphology of the thorax, facilitates thoracic physiotherapy, and seems to slow the decline of vital capacity $[12,19]$. In France, the "Portabird 2" apparatus is used with an abdominal girdle in two $30 \mathrm{~min}$ sessions daily.

This study lists the diagnosis and treatment for children entering ANTADIR system for home treatment for CRF. But the treatment is prescribed by the child's physician. ANTADIR can advise but not change a treatment. This is the reason why one child received oxygen therapy and not MV for Ondine's syndrome. Precise national guidelines for LTOT and MV in children would be appreciated.

The prognosis of CRF in children is of major interest. In contrast to adults, some causes of childhood CRF can improve with growth such as BPD. This disease is related to an early oxidative and barometric insult to the immature lungs. The first 2 yrs of life constitute a period of active alveolar multiplication followed by an increase in alveolar volume up to the age of $8 \mathrm{yrs}$ [20]. This normal lung growth explains why, in contrast to adults, CRF can improve with time in infants with BPD. Our study illustrates this fact, as 17 of the 18 children in whom treatment was stopped because of clinical improvement had suffered from BPD.

Few paediatric studies have analysed the effect of LTOT or MV on survival of children with CRF. BPD is probably the disease in which the benefit of LTOT has been most clearly shown $[21,22]$. LTOT decreases or corrects pulmonary hypertension and the risk of cor pulmonale. In other diseases, such as CF, the benefit of LTOT has not been clearly established [23]. For children with a neuromuscular disease, particularly those with Duchenne's muscular dystrophy, MV may be detrimental when started too early before the onset of a severe restrictive lung disease [24].

Finally, home treatment is valuable when it is both cost-saving and presents psychological advantages for the child and his family [2]. Most of the children attended school. This is one of the most important aspects and shows that the children are able to lead active lives, contributing usefully to their families as well as to society in general. However, despite improvements in home equipment, home-care may not be the most beneficial choice for a given family and other alternatives must be considered.

Home treatment for children with CRF is well-developed in France via the ANTADIR network. Causes of CRF are heterogeneous, with specific treatments and prognoses. The overall prognosis is relatively good, with only nine deaths in this large prospective study. Further improvements could be achieved by comparing the effect of treatments on prognosis and survival. The psychological aspects of these treatments also merit further attention.

\begin{abstract}
Acknowledgements: The authors wish to thank the participating associations: Don du souffle Besançon; AVAD Bordeaux; AIRRA Clermont-Ferrand; Alize de Bourgogne Dijon; ATIRE Evreux; AGIR Grenoble; AVAD Lille; ARARD Marseille; APARD Montpellier; AIR Mulhouse; ARAIRLOR Nancy; ARIRPLO Nantes; CARDIF Paris; ADEP Paris; ARAIRCHAR Reims; ARARR la Réunion; AADAIRC Rochefort; ADIR Rouen; ADIRAL Strasbourg; BAARD Toulouse; SADIR Toulouse.
\end{abstract}

\section{References}

1. Goldberg Al. Technology assessment and support of lifesustaining devices in home-care: the homecare physician perspective. Chest 1994; 105: 1448-1453.

2. Eigen H, Zander J. Home mechanical ventilation of pediatric patients. Am Rev Respir Dis 1990; 141: 258-259.

3. Gaultier C, Boulé M, Allaire M, Clément A, Bucry A, Girard F. Determination of capillary oxygen tension in infants and children. Bull Eur Physipathol Respir 1978; 14: 287-297.

4. Sauve RS, McMillan DD, Mitchell I, Creighton D, Hindle NW, Young L. Home oxygen therapy: outcome of infants discharged from NICV on continuous treatment. Clin Pediatr 1939; 28: 113-119.

5. Robinson RO. Ventilator dependency in the United Kingdom. Arch Dis Child 1990; 65: 1235-1236.

6. Gillis J, Tibbals J, McEneiry J. Ventilator dependent children. Med J Aust 1989; 150: 10-14.

7. Frates RC, Splaingard ML, Harrison GM. Outcome of home mechanical ventilation in children. J Pediatr 1985; 106: 850856.

8. Burr BH, Gueyer B, Todres ID. Home-care for children on respirators. N Engl J Med 1933; 309: 1319-1323.

9. Schreiner MS, Donar ME, Kettrick RG. Pediatric home mechanical ventilation. Pediatr Clin North Am 1987; 34: 47_ 60.

10. Splaingard ML, Frates RC, Harrison GM. Home positivepressure ventilation: twenty years experience. Chest 1983 84: 376-382.

11. O'Leary J, King R, Leblanc M, Moss R, Liebhaber M, Lewiston N. Cuirass ventilation in childhood neuromuscular disease. J Pediatr 1979; 94: 419-421.

12. Barois A, Estournet-Mathiaud B. Ventilatory support at home in children with spinal muscular atrophies (SMA). Eur Respir Rev 1992; 2: 319-322.

13. Muir JF, Voisin C, Ludot A. Home mechanical ventilation (HMV): national insurance system (France). Eur Respir Rev 1992; 2: 418-422.

14. Hodson ME, Madden BP, Steven MH, Tsang VT, Yacoub $\mathrm{MH}$. Noninvasive mechanical ventilation for cystic fibrosis patients: a potential bridge to transplantations. Eur Respir J 1991; 4: 524-527. 
15. Piper AJ, Parker S, Torzillo PJ, Sullivan CE, Bye PTP. Nocturnal nasal IPPC stabilizes patients with cystic fibrosis and hypercapnic respiratory failure. Chest 1992; 102: 846850.

16. Baculard A, Bedicam JM, Sardet A, Fauroux B, Tournier G. Ventilation mécanique par masque nasal en pression positive intermittente chez l'enfant atteint de mucoviscidose. Arch Fr Pediatr 1993; 50; 469-474.

17. Baculard A, Sardet A, Boule M, Fauroux B, Tournier G. Nasal intermittent positive pressure ventilation (NIPPV) for cystic fibrosis (CF) patients with severe chronic respiratory failure (CRF). In: Clinic Ecology of Cystic Fibrosis Elsevier Publishers M.V. 1993; pp. 213-217.

18. Léger P, Bedicam JM, Cornette A, et al. Nasal intermittent positive pressure ventilation: long-term follow-up in patients with severe chronic respiratory failure. Chest 1994; 105: 100-105.

19. Estournet-Mathiaud B, Barois A. Home treatment of severe bronchopulmonary dysplasias: oxygen therapy and assisted ventilation. Eur Respir Rev 1992; 2: 304 307.

20. Gaultier C, Girard F. Croissance pulmonaire normale et pathologique: relations, structure, formation. Bull Eur Physiopathol Respir 1980; 16: 791-842.

21. Fourou JC, Le Guennec JC, Villemant D, et al. Value of echocardiography in assessing the outcome of bronchopulmonary dysplasia of the newborn. Pediatrics 1980; 65: 529.

22. Abdam SH, Wolfe RR, Accurso FJ, Koops BL, Boroman M, Wiggius JW. Pulmonary vascular response to oxygen in infants with severe bronchopulmonary dysplasia. Pediatrics 1985; 75: 80-84.

23. Zinman R, Corey M, Coates AL, et al. Nocturnal home oxygen in the treatment of hypoxemic cystic fibrosis patients. J Pediatr 1989; 114: 368-377.

24. Raphael JC, Chevret S, Chastang C, Bouvet F. Randomised trial of preventive nasal ventilation in Duchenne muscular dystrophy. Lancet 1994; 343: 1600-1604. 